\title{
ENSURING PATIENT SAFETY IN THE NEW OPERATING THEATRE OF UMMC TRAUMA CENTRE; AN ANAESTHESIOLOGIST NOVICE EXPERIENCE
}

\author{
Mamat $M^{1}$, Chan $L^{2}$ \\ ${ }^{1}$ Faculty of Medicine, Universiti Teknologi Mara (UiTM), Malaysia \\ ${ }^{2}$ Department of Anaesthesiology, Faculty of Medicine, Universiti Malaya, Kuala Lumpur
}

\begin{abstract}
Patient safety is a serious global healthcare issue. Harm can be caused by a range of errors or adverse events. Therefore, it is vital that the commissioning of a new operating theatre should comply to the highest standard before it is allowed to function. This paper accounts our experience in the commissioning of the University Malaya Medical Centre (UMMC) trauma centre operating theatre (OT) complex in July 2008. We highlighted the problems we faced in adhering to the international standard guidelines. Unanticipated events were handled professionally and solved. With this experience, we hope that the identified problems would provide suggestions for commissioning an operating theatre in the local setting in the future. (JUMMEC 2009; 12 (2): 83-91)
\end{abstract}

KEYWORDS: patient safety, operating theatre commission.

\section{Introduction}

Under the 7th Malaysian Plan, a modern trauma and emergency centre was constructed at the forefront of the University Malaya Medical Centre (UMMC). It became operational in 2003. However, the operating theatre (OT) which was designed to compliment urgent emergency surgeries never took off for various reasons. It was not until recently, after an understanding between the UMMC OT committee members that the long awaited functioning of the trauma centre OT came into existence. The need is timely with the increasing emergency surgeries done in the main OT complex.

The Anaesthesiology Department, UMMC was given the responsibility to check and certify that the OT was safe for use. The safety issues included all aspects of patient's care and the needs and services of healthcare staff and supporting staff.

\section{Objective}

Patient safety is a serious global healthcare issue. Estimates showed that in developed countries, 10\% was harmed while receiving hospital care (1). The harm can be caused by a range of errors or adverse events. Therefore it is vital that the OT inspection should comply to the highest standard and "zero-defect" from avoidable causes.
We hope that we can identify in the local setting common problems associated with commissioning an OT in UMMC.

\section{Methodology}

The Anaesthesiology Department team members comprised of a clinical consultant and two medical officers (one senior medical officer and a Master of Anaesthesiology trainee). We were supported by the nursing team which comprised the matron, two sisters, and five staff nurses.

A checklist, which complied to the World Health Organisation (WHO) standards, the recommended minimum OT facilities guidelines set by the Australian and New Zealand College of Anaesthestists (ANZCA) and the standards set by the Ministry of Health of Malaysia (2-6), was prepared by the consultant anaesthesiologist. The checklist was divided into two parts: the physical aspects and the patient related aspects. The inspection

\footnotetext{
Correspondance :

Mafeitzeral Mamat

Department of Anaesthesiology,

Faculty of Medicine, Universiti Malaya,

50603, Kuala Lumpur, Malaysia

Email:mafeitz@gmail.com
} 
and ratification was done on the 7th and 8th of July, 2008. The OT started its first case on the 9th of July, 2008.

In this exercise, if the OT was found to be unsatisfactory, surgical operations were postponed to a later date after the major problems were rectified. This consensus was in tandem with upholding patients' safety.

\section{Results}

Using the prepared checklist, we double checked with the UMMC Engineering team with the cooperation of the Microbiology Department that they had completed the steps below (done between weeks 1 June and 30 June, 2008:

1. The OT interior was checked for obvious defects

2. The air distribution within the theatre and between rooms in the theatre suite was satisfactory. The air handling unit supplying the theatre was properly constructed, the theatre was properly constructed, finished and functioning

3. The air change rates in OT and preparation room wa satisfactory

4. Airborne microbial contamination in an empty OT was satisfactory (ICT)

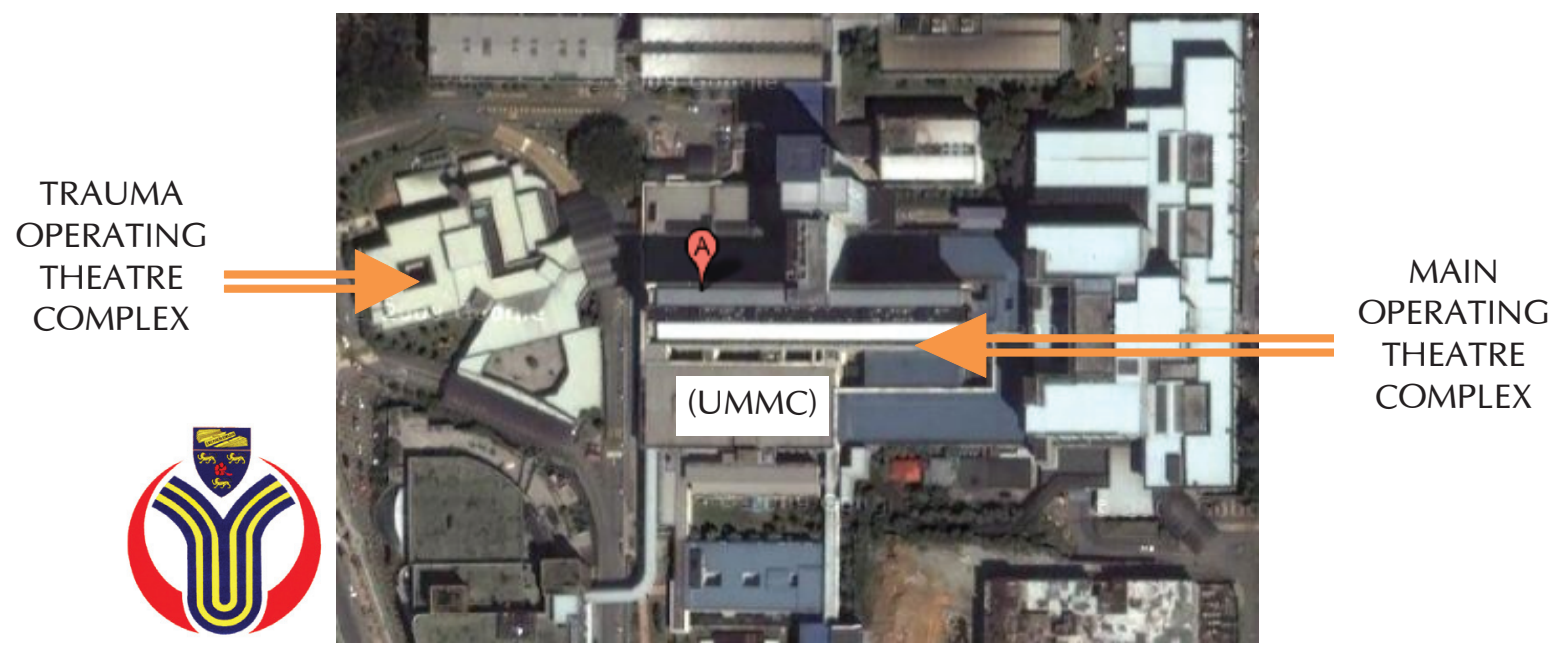

Figure 1: The Universiti Malaya Medical Centre (UMMC) complex

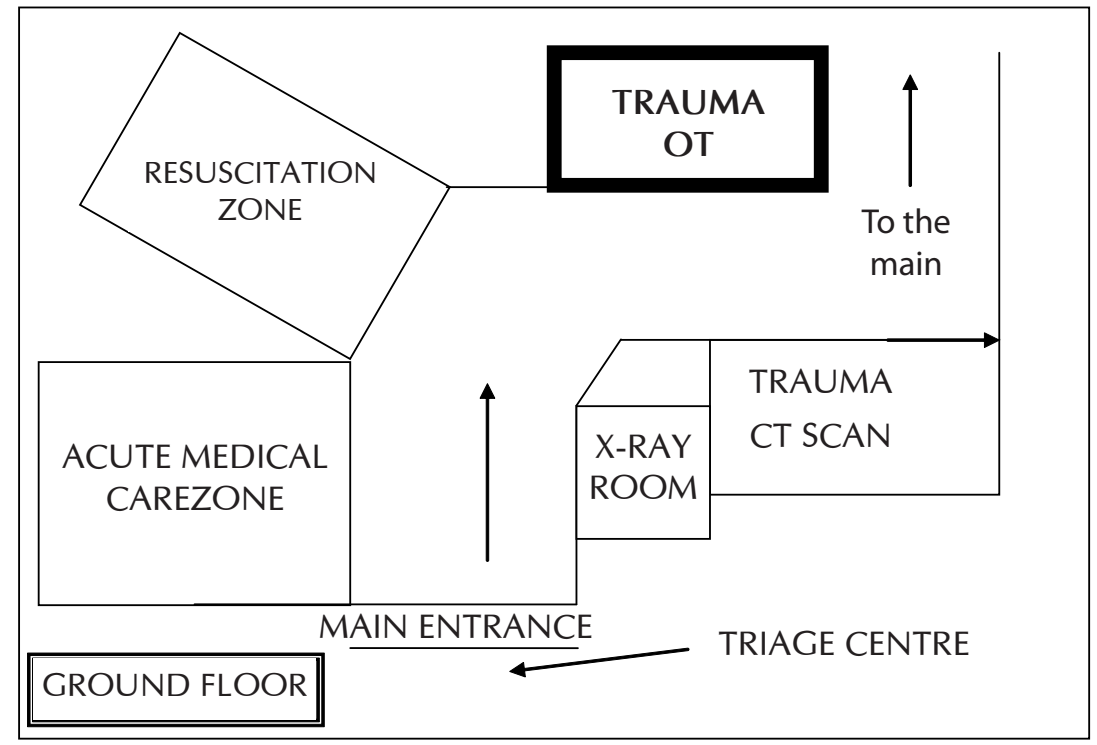

FRONT OF TRAUMA CENTRE

Figure 2: Trauma Operating Theatre (OT) in the Trauma and Emergency Centre 
The commissioning checklist was divided into two parts: the physical aspects and the patient related aspects. There were few sub sections that went under vigorous scrutiny. Being abandoned for several years, there were lots of technical glitches which needed to be rectified. Most of the problems with equipment arose from its non-usage for several years.

\section{Physical Aspects}

\begin{tabular}{|c|c|c|c|}
\hline \multirow{3}{*}{ 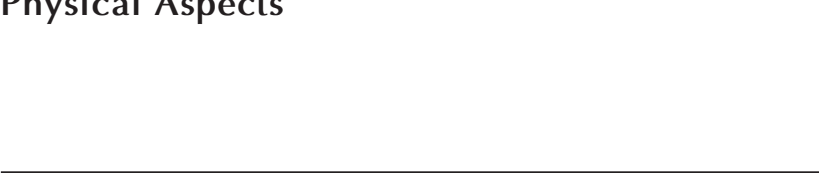 } & \multirow{2}{*}{\multicolumn{2}{|c|}{7 July 2009}} & \multirow{3}{*}{$\begin{array}{c}8 \text { July } 2009 \\
\begin{array}{c}\text { Satisfactory And } \\
\text { Rectified }\end{array} \\
\end{array}$} \\
\hline & & & \\
\hline & $\begin{array}{l}\text { Satisfactory } \\
\text { Y/N }\end{array}$ & $\begin{array}{l}\text { Immediate Attention } \\
\text { and Action }\end{array}$ & \\
\hline Reception & N & Phone faulty & $\sqrt{ }$ \\
\hline Changing Room & $\mathrm{Y}$ & & $\sqrt{ }$ \\
\hline Transfer Bay & $\mathrm{Y}$ & & $\sqrt{ }$ \\
\hline $\begin{array}{l}\text { OT } 1 \text { safe practice: } \\
- \text { Warning devices in medical gas pipeline systems, } \\
\text { to alarm when bulk gas supplies are low. }\end{array}$ & N & Engineering & $\sqrt{ }$ \\
\hline $\begin{array}{l}\text { - Electrical supply and equipment designed to } \\
\text { eliminate risk of microshock. }\end{array}$ & Y & & $\sqrt{ }$ \\
\hline - Emergency lighting and power supply. & N & Engineering & $\sqrt{ }$ \\
\hline $\begin{array}{l}\text { - Means of controlling the temperature within } \\
\text { the range of } 20^{\circ} \mathrm{C} \text { to } 28^{\circ} \mathrm{C} \text {. }\end{array}$ & N & Engineering & $\sqrt{ }$ \\
\hline - A wall clock with a sweep second hand. & N & Not working & $\sqrt{ }$ \\
\hline $\begin{array}{l}\text { - Provision for scavenging waste anaesthetic } \\
\text { gases and vapours. }\end{array}$ & N & Engineering & $\sqrt{ }$ \\
\hline $\begin{array}{l}\text { - Means of communicating with persons outside } \\
\text { theatre. }\end{array}$ & Y & & $\sqrt{ }$ \\
\hline $\begin{array}{l}\text { - Separate refrigerators: correct storage of blood } \\
\text { and biological products. }\end{array}$ & Y & & $\sqrt{ }$ \\
\hline $\begin{array}{l}\text { Standard equipment } \\
-12 \text {-lead electrocardiograph. }\end{array}$ & $Y$ & & $\sqrt{ }$ \\
\hline - A defibrillator. & Y & & $\sqrt{ }$ \\
\hline $\begin{array}{l}\text { - A manual, self-inflating resuscitator bag capable } \\
\text { of delivering up to } 100 \% \text { oxygen (e.g. Laerdal, } \\
\text { Ambu bags). }\end{array}$ & Y & & $\sqrt{ }$ \\
\hline - Central venous pressure sets. & N & OT Staff & $\sqrt{ }$ \\
\hline $\begin{array}{l}\text { - Means of infusing intravenous fluids under } \\
\text { pressure. }\end{array}$ & Y & & $\sqrt{ }$ \\
\hline - Blood warming apparatus. & Y & & $\sqrt{ }$ \\
\hline - Means of insulating the patient against heat loss. & Y & & $\sqrt{ }$ \\
\hline $\begin{array}{l}\text { - Means of providing or conserving airway } \\
\text { humidification. }\end{array}$ & Y & & $\sqrt{ }$ \\
\hline - Intercostal catheter drainage set. & N & OT Staff & $\sqrt{ }$ \\
\hline $\begin{array}{l}\text { - Trays suitable for spinal, epidural and regional } \\
\text { nerve blocks. }\end{array}$ & Y & & $\sqrt{ }$ \\
\hline - Equipment for difficult intubations. & Y & & $\sqrt{ }$ \\
\hline — Patient trolleys capable of rapid tilting. & Y & & $\sqrt{ }$ \\
\hline $\begin{array}{l}\text { - A refrigerator for the storage of drugs required } \\
\text { to be stored in the cold. }\end{array}$ & N & & $\sqrt{ }$ \\
\hline
\end{tabular}




\section{Physical Aspects (continued)}

\begin{tabular}{|c|c|c|c|}
\hline & \multicolumn{2}{|c|}{7 July 2009} & \multirow{2}{*}{$\begin{array}{c}\text { July } 2009 \\
\begin{array}{l}\text { Satisfactory And } \\
\text { Rectified }\end{array}\end{array}$} \\
\hline & $\begin{array}{l}\text { Satisfactory } \\
\mathrm{Y} / \mathrm{N}\end{array}$ & $\begin{array}{l}\text { Immediate Atten- } \\
\text { tion and Action }\end{array}$ & \\
\hline \multirow{2}{*}{\multicolumn{4}{|c|}{$\begin{array}{l}\text { Anaesthesia equipment } \\
\text { 1. Each anaesthetic machine must have the } \\
\text { following safety features: }\end{array}$}} \\
\hline & & & \\
\hline a) An indexed gas connection system. & $Y$ & & $\sqrt{ }$ \\
\hline $\begin{array}{l}\text { b) A reserve cylinder supply of oxygen and, where } \\
\text { appropriate, nitrous oxide. }\end{array}$ & $\mathrm{N}$ & OT Staff & $\sqrt{ }$ \\
\hline c) An oxygen supply pressure warning device. & Y & & $\sqrt{ }$ \\
\hline $\begin{array}{l}\text { d) An oxygen analyser/monitor with a low oxygen } \\
\text { alarm. }\end{array}$ & $Y$ & & $\sqrt{ }$ \\
\hline e) Each anaesthetic machine should include: & & & \\
\hline $\begin{array}{l}\text { (i) Calibrated vaporisers for accurate delivery of } \\
\text { inhalational anaesthetics. }\end{array}$ & $Y$ & & $\sqrt{ }$ \\
\hline (ii) A range of suitable breathing systems. & $\mathrm{Y}$ & & $\sqrt{ }$ \\
\hline $\begin{array}{l}\text { (iii) Breathing systems suitable for paediatric } \\
\text { anaesthesia }\end{array}$ & $Y$ & & $\sqrt{ }$ \\
\hline $\begin{array}{l}\text { 2. An automatic mechanical ventilator, with a } \\
\text { disconnection alarm, must be available for } \\
\text { each anaesthetised patient. }\end{array}$ & Y & & $\sqrt{ }$ \\
\hline $\begin{array}{l}\text { 3. Suction apparatus } \\
\text { (complying with BS4199, AS2120 or } \\
\text { equivalent), including hand pieces (e.g. } \\
\text { Yankauer) and a range of endotracheal } \\
\text { catheters, for the exclusive use of the } \\
\text { anaesthesiologist. }\end{array}$ & Y & & $\sqrt{ }$ \\
\hline 4. Alternative suction system & Y & & $\sqrt{ }$ \\
\hline 5. Standard intubation equipment & $\mathrm{Y}$ & & $\sqrt{ }$ \\
\hline Recovery Area & Y & & $\sqrt{ }$ \\
\hline
\end{tabular}

\section{Patient Related Aspects}

\begin{tabular}{|l|c|c|c|}
\cline { 2 - 4 } \multicolumn{1}{c|}{} & \multicolumn{2}{c|}{7 July 2009 } & 8 July 2009 \\
\cline { 2 - 4 } \multicolumn{1}{c|}{} & $\begin{array}{c}\text { Satisfactory } \\
\text { Y/N }\end{array}$ & $\begin{array}{c}\text { Immediate Atten- } \\
\text { tion and Action }\end{array}$ & $\begin{array}{c}\text { Satisfactory And } \\
\text { Rectified }\end{array}$ \\
\hline Identification and transfer flow checkist & $Y$ & $\sqrt{ }$ \\
\hline Linen and clothing & $Y$ & $\sqrt{ }$ \\
\hline Job description & N & Consultant and Matron & $\sqrt{ }$ \\
\hline Patient Selection Criteria & Y & & $\sqrt{ }$ \\
\hline Protocols and Guidelines & $\mathrm{N}$ & Matron & $\sqrt{ }$ \\
\hline
\end{tabular}




\section{Discussion}

Surgery is one of the most complex health interventions to deliver. More than 100 million people in the world receive surgical treatment every year for various reasons. Problems associated with surgical and anaesthetic safety in developed countries account for half of the avoidable adverse events that result in morbidity and mortality (1).

We were fairly satisfied with the audit done on the 7th of July. Most of the important details of the checklist were fulfilled but there were few issues which needed immediate active intervention which is discussed in the subheadings below.

\section{Infrastructure}

The UMMC Trauma Centre OT mini complex is situated $100 \mathrm{~m}$ from the main operating theatre complex of the UMMC main building (Figure 1). The infrastructure has been unused since 2003. There were attempts to run it previously, but it did not materialize because of theatre design flaws, which were not anticipated. The piping system and ceiling height were the main culprits of its non functioning status. Hence, the OT was renovated several times. All renovation were completed by March 2007. Human resource was another limiting factor due to the busy day to day running of the main OT. It was almost impossible to run another facility which was physically apart from the centre of command.

The trauma OT is situated next to the resuscitation zone and opposite the CT scan room on the trauma centre ground floor (Figure 2). It consists of two bedded reception area, two bedded recovery area, two changing room facilities and two functional operating theatres with its sub sections.

It was designed to facilitate urgent emergency surgeries; ideal for efficiency in ensuring optimal management for the patient's sake. Previously, emergency surgical patients had to travel a distance (with inclining slopes!) from the trauma centre to the main OT complex. This has resulted numerous unwanted events like cardiac arrest during transport. According to Szem et al, intra-hospital transfer for inpatients carry a significant morbidity and mortality risk. The morbidity and mortality risk increases in relation to the distance travelling by critically ill patients the further the critically ill patient travels (7).

\section{Medical gas system}

We had discussions with various divisions of UMMC engineers to sort out the problems that we came across. For example, the selected wall and attached facility gas outlets in both the main OT complex and the mini UMMC trauma centre OT were faulty. This can
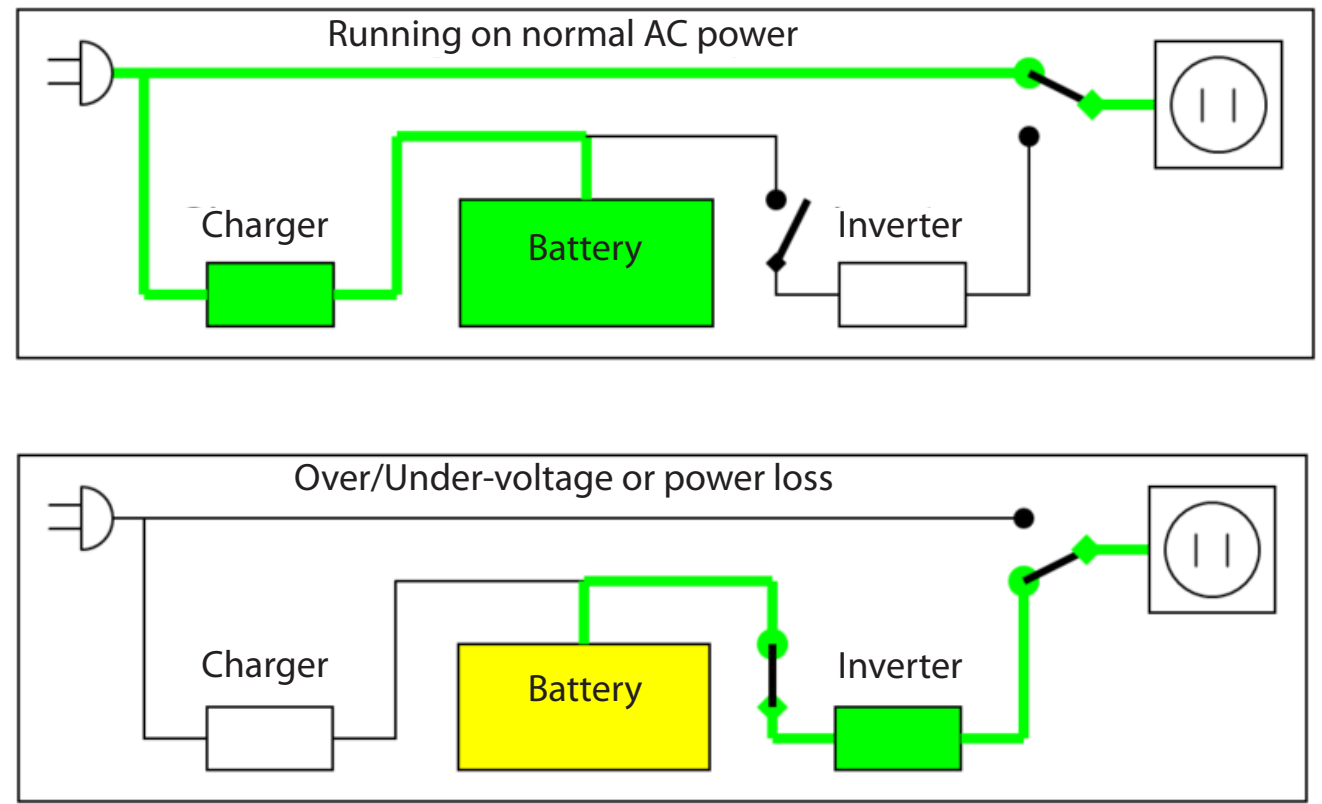

Figure 3: Simple, easy-to-understand diagram of how a Standby UPS works. 
be a cardinal sin as malfunctioning of the medical gas systems especially oxygen can endanger patients. We were unable to secure connections (failed "tug test") to both the oxygen and nitrous oxide gas outlets. One of the oxygen outlets was faulty as no oxygen flow was detected.

After a thorough inspection by the gas engineers, the problem was caused by the faulty hose outlet because it was unused for several years. Hypothetical cross piping that would cause mixture of nitrous oxide and oxygen supply should be detected by the gas analyzer in the General Anaesthetic machine (4).

Another problem that was detected was the scavenging suction system that was not functioning when checked. This is an important component as its malfunction can cause gas pollution, which in turn can create a hazardous environment to the servicing doctors and nurses. It was later discovered that the central line suction pump was faulty and immediately rectified.

\section{Electrical safety and system}

We were unable to objectively ensure electrical safety for both healthcare workers and patients according to international practice $(6,12)$. However, we were reassured by the UMMC electrical engineering team that all circuits were grounded and the hazard of microshock was minimal. We were briefed regarding the Trauma Centre's electrical safety backup (i.e. backup generator, UPS) in case of power failure. At all times in case of power failure from the main supplier, Tenaga Nasional Berhad, the trauma OT should always have adequate electrical supply by either the backup generator or the UPS system. (Figure 3)

On the 8 July, 2008, we experienced an "unintentional" blackout. It was here that we managed to identify the core electrical supply of the mini OT in the UMMC trauma centre. It was revealed later that the renovation work behind the trauma centre accidentally caused a main cable cut which was quickly repaired.

The OT lights were intermittently malfunctioning caused by the main supply wire. It was also noticed that few light bulbs were faulty. Emergency lights were obviously absent in certain parts of the complex. The UMMC Electrical division was notified and the necessary adjustments were performed immediately.

\section{Environmental factors}

The temperature, humidity and ventilation systems were inspected and found to be satisfactory. The controls and indicator were working well. However,

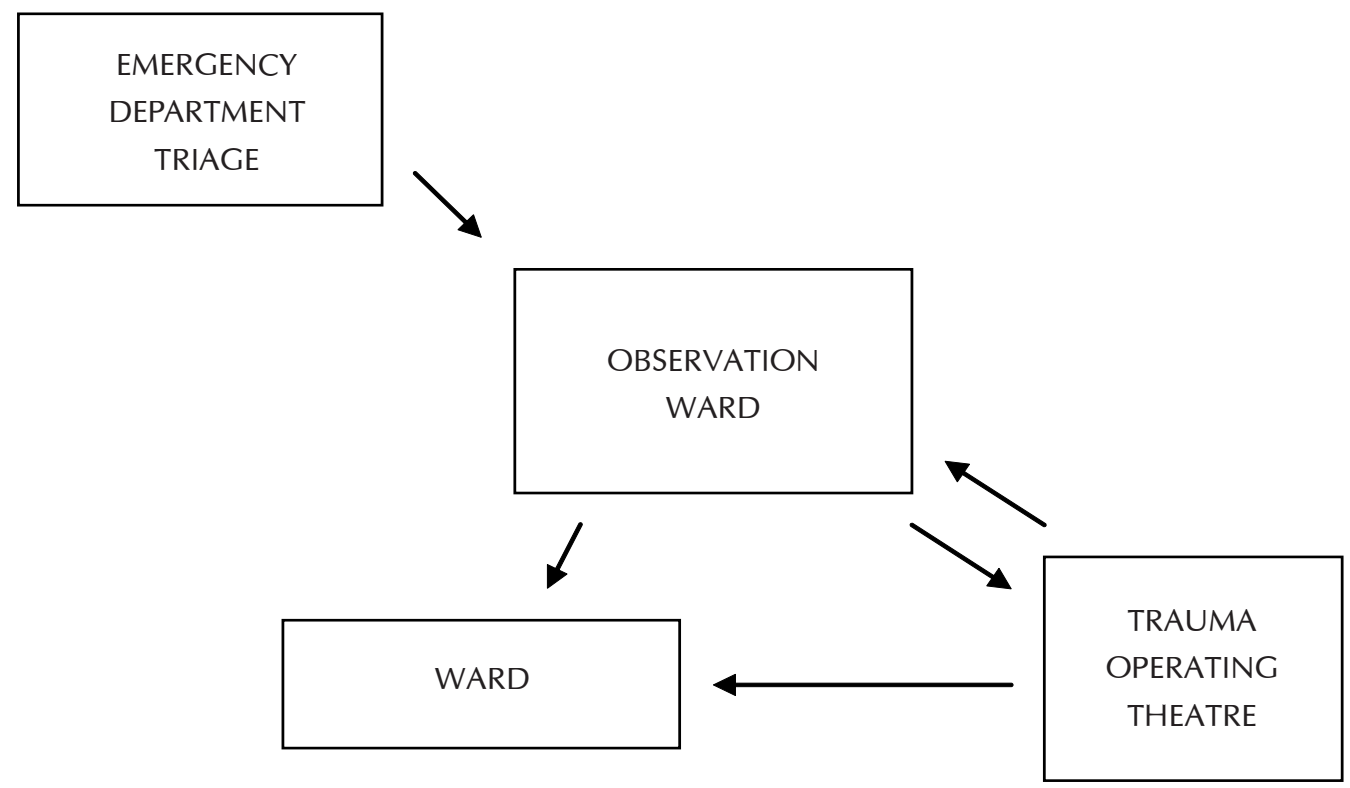

Figure 4: Patient flow from triage to Trauma OT not to scale) 
due to power failure of the Trauma Centre on 8 July, 2008, because of ongoing construction works in the UMMC compound, the air conditioning system was not functioning. This caused high humidity and moderate temperature rise that caused both theatres to be wet and hazardous. The first case planned on the 9th of July nearly did not materialize. With the help from the engineering department, the failure was rectified.

Fire extinguishers were in good condition and placed at critical areas. Emergency exits were also easily identified and accessible.

\section{Equipment}

Both theatres were equipped with two Datex Ohmeda Aestiva 5 anaesthetic machines. They were brand new and we checked the functional status thoroughly by following the standard operating manual provided by the manufacturer. The general manager of the company that supplied the machines was also present. He counter checked and confirmed that the machines were safe to be used on patients.

Other monitoring devices were also inspected and certified fit to be used. All the monitoring devices were in accordance with the minimal monitoring standards as prescribed by ANZCA and Ministry of Health, Malaysia $(3,5)$.

Besides that, the intubation trolley, resuscitation trolley and the difficult airway trolley were strictly audited and checked to ensure that every single equipment was available and in good working condition.

\section{Patient-related aspects checklist}

The second part of the checklist was patient-related where the issues were on the administrative in nature. Effective communication between surgeons, anaesthetists and OT staff is vital for optimal patient care (11). The booking system and patient flow were thoroughly discussed between the Anaesthesiology Consultant with the operating theatre staff. Accurate documentation was necessary and it was to be complimented by smooth patient flow (Figure 4 ).

As agreed in the earlier meetings of the OT committee, when the OT is found to be satisfactory, it would undergo a two month trial. Patients who were to be operated in this theatre would adhere to few selection guidelines (Table 1). It was hoped that all minor details would be sorted out before the OT could accept "TRUE" trauma surgeries.

Table 1: Patient Selection for Trauma OT

\begin{tabular}{ll}
\hline Criteria & \\
\hline $\begin{array}{l}\text { American } \\
\text { Anaesty of } \\
\text { (ASA) Class }\end{array}$ & I and II \\
\hline Patient selection & Adult 18 and above \\
& Children 2 - 5: needs discussion \\
& Children<2: not suitable \\
\hline Consent & Next of kin not allowed \\
\hline Duration & Maximum 2 hours \\
\hline Type of surgery & Haemodynamically stable patients with \\
& established diagnosis \\
& Example of surgeries: \\
& Surgery: \\
& Appendicectomy \\
& Wound debridement for leg ulcers \\
& Toilet and Suturing for cuts \\
& ICP monitor insertion \\
& Burr Hole \\
& Orthopaedics: \\
& Open fracture wound debridement \\
& Diabetic foot ulcer debridement \\
\hline Gype of & General Anaesthesia without invasive \\
monitoring \\
Regional Anaesthesia \\
Local Anaesthesia
\end{tabular}

\section{Implementation}

On the 9th of July, 2008, there were two cases booked by the general surgery team. Only one case fulfilled the strict criteria (Table 1). The case was informed to the consultant anaesthetist in charge and she gave the green light. However, it was discovered that the theatres were all wet as a result of the impaired air conditioning. The temperature in the OT was $28^{\circ} \mathrm{C}$ and humidity at $90 \%$ because of the power failure in the trauma centre complex the previous day. The repair work was still in progress on the 9th of July, 2008. The UMMC engineers rectified the problem by 10.30 a.m. and we were satisfied with the theatre's condition at 11.45 a.m. 
A 39 year old Cambodian lady ASA 1 was planned for appendicectomy after the surgeons confirmed her clinical and investigative findings. She was admitted at 10.15 p.m. the previous night and placed in the observation ward. She was assessed by the anaesthesia trainee early in the following morning. The patient was anaesthetized at 12.10 p.m. The surgery was done within the one hour window and safely extubated. It was uneventful.

She was haemodynamically stable in the recovery area and did not require any further analgesics during her 30-minute observation there. She was later brought to the surgical ward at 2.30 p.m.

An immediate "post mortem" was done by all the staff in charge to trouble shoot and review all problems that impaired patient flow throughout the surgery. It was recorded down on a designated logbook for audit and future reference.

\section{Conclusion}

A patient's safety remains as the anaesthesiologists' main priority as perioperative physician. The anaesthesiologist takes full responsibility of the patient as soon as he or she steps into an OT $(2,5)$. This would concur to the Joint Commision International (JCl) accreditation philosophy in setting standards for hospitals focused on one goal: raising the safety and quality of care to the highest possible level (13).

Managing an OT complex may appear simple but there are many aspects to be looked into prior to starting any case. The first few chapters in any standard Anaesthesiology textbooks emphasise these issues in detail. Perfection is mandatory and morbidities and mortalities should be prevented $(8,9)$.

Efficient teamwork is vital to success in any interdisciplinary initiatives. In operating theatres, the cooperation and multilateral understanding between the doctors, nurses, supporting staff and ground staff ensures smooth operational OT flow (10). Preventing unnecessary delay in patient care will contribute to better outcome as well as reducing economic costs. Hopefully, the opening of UMMC trauma centre OT complex will pave way for more efficient use of time, optimal patient safety and minimize unnecessary resource allocation for the local setting.

\section{References}

1. WHO Patient Safety. World Health Organisation. Available from http://www.who.int/patientsafety/ en/index.html. Accessed June 2009.

2. Anaesthesia and Intensive Care Service, Operational Policy. MOH/P/PAK/142.07 (BP) February 2008.

3. Academy Of Medicine Malaysia, Chapter of Anaesthesiologists, April 2003. Recommendations for Safety Standards and Monitoring During Anaesthesia and Recovery.

4. Australia and New Zealand College of Anaesthesiologists 2003, P31. Recommendations on Checking the Anaesthetic Delivery System.

5. Australia and New Zealand College of Anaesthesiologists. T12000. Recommendations on Minimum Facilities for Safe Anaesthesia Practice in Operating Suites.

6. Malaysian Standards approved on 21/02/2007 by the Ministry of science, technology and innovation in accordance with the standards of Malaysian Act(ACT 549) ISC D: Building and Civil Engineering, ISC E: Electrotechnical, ISC R: Medical Devices.

7. Szem JW, Hydo LJ, Fischer E, Kapur S, Klemperer $\mathrm{J}$, Barie PS. High-risk intrahospital transport of critically ill patients: safety and outcome of the necessary "road trip". Crit Care Med 1995; 23: 16601666.

8. Morgan GE, Mikhaeil MS, Murray MJ, Larson CP. Clinical anaesthesiology. 3rd Ed. NY: McGraw Hill, 2002.

9. Bland H. The supply of anaesthetic and other medical gases. In: Davey AJ, Diba A. ed. Ward's Anaesthetic Equipment. 5th Ed. Philadelphia: Elsevier; 2005: 23-47.

10. Reason J. Safety in the operating theatre-Part 2: Human error and organisational failure Qual Saf Health Care 2005; 14: 56-60 .

11. Schaefer HG, Helmreich RL, Scheidegger D. Safety in the operating theatre-part 1: interpersonal relationships and team performance. Current Anaesthesia Critical Care. 1995; 6: 48-53. 
12. Boumphrey $S$, Langton. JA Electrical safety in the operating theatre. $\mathrm{Br} J$ of Anaesthesi CEPD Reviews. Feb 2003 1: 1.10-14(5).

13. Joint Commission International $(\mathrm{JCl})$, WHO Collaborating Centre. Available from http://www. jointcommissioninternational.org/about-jci/. Accessed June 2009. 